\title{
An Evaluation of Drug Dosage Calculation Knowledge and Proficiency among Newly Hired Nurses in Private Tertiary Care Hospital, Islamabad, Pakistan
}

\author{
Article by Nuzhat Sultana \\ Director Nursing Education Services, Shifa International Hospital Islamabad, Pakistan \\ Email:nuzhatsultana@hotmail.com
}

\begin{abstract}
Background: Drug dosage calculation and administration is important function of nurses. The key professional role of nurses is to ensure safe drug dosage calculation while performing medication administration. Medication errors are a common cause of adverse events that may result due to wrong drug dosage calculation. The assessment of nurse's knowledge related to drug dosage calculation has not been conducted at the time of commencing their employment in the study hospital.

Purpose: The purpose of this study was to assess the drug dosage calculation knowledge and proficiency among our newly hired nurses before and after the training session.

Method and design: Participatory Action Research (PAR) approach was selected using pre and post -test to assess the newly hired nurse's knowledge and proficiency related to drug dosage calculation. Data was collected after IRB approval at private tertiary hospital, Islamabad, Pakistan.

Sample: Purposive sampling technique was adopted $(n=135)$ all nurses on their commencement of employment from July 2016 to October 2016 participated in the study after the informed consent.

Findings: The study results showed the significant improvement in drug dosage calculation knowledge and proficiency among the study participants while comparing pre-test and post-test results.

Conclusion: The study concluded in the light of pre-test and post-test results that there is an intense need to review the nurse's drug dosage calculation knowledge and proficiency at the time of employment as nurses are key player in drug preparation and administration.
\end{abstract}

Keywords: Drug dosage calculation, conceptual skills in mathematics, proficiency, an evaluation of drug dosage, essential competency, dosage calculation knowledge, numeracy.

\section{Introduction}

Drug dosage calculation and administration is an important function of nurses. The key professional role of nurses is to ensure safe drug dosage calculation while performing medication administration. Literature indicates that medication errors are a common cause of morbidity and mortality that may results due to wrong drug dosage calculation (Cheragi, Manoocheri, Mohammadnejad, \& Ehsani, 2013; Fleming, Brady, \& Malone, 2014; Freedman et al., 2002; Shamsuddin \& Shafie, 2012). Joint Commission 2008 report high lights medication safety considering it as global issue in patient care (Wright, 2010). The current literature warns that medication errors are most common mistakes worldwide that are threat to patient safety and resulting in escalation of mortality rate, length of hospital stay and related costs (Cheragi, et al., 2013). Further a literature review indicates that there is lack of research in the area of drug dosage calculation proficiency of the nurses that could lead to serious medication errors and threat to patient safety (Wright, 2010). Therefore, this study was planned with the purpose to assess the drug dosage calculation knowledge and proficiency among our newly hired nurses using pre-test and post test approach.

\section{Study question}

What is the level of knowledge and competence of newly hired nurses related to drug dosage calculation, as compared to before and after receiving the drug dosage calculation training module at Shifa International Hospital, Islamabad? 
i. Are our newly hired nurses proficient in drug dosage calculation and conversion system for oral, intramuscular, intravenous and continuous intravenous infusions?

ii. Are our newly hired nurses skillful in micro and macro drug dosage calculation?

iii. Are our newly hired nurses accurate to calculate blood transfusion rate and inotropic infusions (lifesaving drugs)?

The study aimed to answer the above mentioned questions. The study results indicated the significant difference in nurse's knowledge and proficiency in drug dosage calculation as compared to before and after the intervention. The pre-test shows $(n=40) 29.63 \%$ performed poor, $(n=39) 28.89 \%$ achieved average score, $(n=48) 35.56 \%$ of the nurses scored good or very good and very few $(n=8)$ $5.92 \%$ achieved excellent scoring 40.5- $<50$. While in post-test $(n=111) 82.22 \%$ achieved excellent and $(n=58 / 111) 42.96 \%$ achieved $100 \%$ accuracy score.

Limitations of the study: The study sample was small and could not generalize the results. However, the implication of the study is in nursing practice, nursing education, nursing research and nursing administration that warrant future researches.

\section{Literature review}

\section{Drug dosage calculation errors}

Recent literature defines wrong drug dosage error as an inconsistency between the dose administered and the dose prescribed (Wright, 2010). Medication safety is a major concern and a global issue related to quality and safety of patient care (Savage, 2015; Shamsuddin \& Shafie, 2012). A study conducted on economic measurement of medical errors in hospital setting reported that 44,000 to 98,000 medical errors cause serious adverse event every year in the United States (David, Gunnarsson, Waters, Horblyuk, \& Kaplan, 2013). An empirical study identified that drug dosage calculation errors remained under- investigated and calls an immediate consideration for future studies (Wright, 2010).

Mathematical and dosage calculation proficiency is very important skill for nurses in order to ensure patient safety and delivery of quality care (Athanasakis, 2012; Cheragi, et al., 2013; Fleming, et al., 2014; Savage, 2015; Sulosaari et al., 2015; Wright, 2004). Recent review of literature reports that presently medication errors are focused in healthcare in the light of official reports in United States and the United Kingdom that highlighted the significant of medication errors occurring in hospitals. A study conducted to evaluate the drug dosage calculation proficiency of registered nurses on commencement of new employment reported that majority of the nurses lack the drug dosage calculation skill (Fleming, et al., 2014). A recent study conducted in Tehran, Iran reported that drug errors are a major problem in nursing care as medication errors are not reported by nursing staff, study suggested that nurse managers must encourage nurses to report medication errors timely (Cheragi, et al., 2013). A study conducted in Finland on drug dosage calculation proficiency among graduating nursing students found that one-fifth of the students failed the numeracy test due to poorly organized medication dosage calculation module (Grandell-Niemi, Hupli, \& Leino-Kilpi, 2001).

\section{Nurses training need for drug dosage calculation}

A significant proportion of errors hint skill and knowledge deficiencies among nurses (Westbrook, Rob, Woods, \& Parry, 2011).

In United Kingdom according to the audit commission National Health Service report (2001) adverse events due to medication errors resulted in nearly $20 \%$ of the deaths that requires immediate attention cited in (Shamsuddin \& Shafie, 2012). Another study conducted in Australia also reported that the tutorial sessions enhanced the accuracy of students' medication dosage calculation and understanding the application of correct formula and identifying errors of drug dosage calculation (Coyne, Needham, \& Rands, 2013). A recent study indicated that drug dosage calculation skills among practicing nurses was greater than graduating nursing students. This study results also indicate that the nurses develop medication knowledge during the first year of practice therefore, the study suggest the need to put more emphasis for on-the-job-training in drug dosage calculation and pharmacological aspect to develop their competence (Simonsen, Daehlin, Johansson, \& Farup, 2014). Literature further indicates that the most frequent type of drug calculation errors are resulted from 
conceptual errors that needs the attention for nurses in-service education for drug dosage calculation (Blais \& Bath, 1992).

Another study identified that the nursing students are not competent in the process of medication therapy both from their own and their clinical instructor's perspectives that calls an urgent need to take actions to strengthen the students' skills in medication administration and dosage calculation (Zare, Purfarzad, \& Adib-Hajbaghery, 2013).

The findings of several research studies have identified the lack of drug dosage calculation skills among nurses (McMullan, Jones, \& Lea, 2010; Shamsuddin \& Shafie, 2012; Sohrevardi, Mirjalili, Jarrahzadeh, Mirjalili, \& Mirzaei, 2014; Tshiamo, Kgositau, Ntsayagae, \& Sabone, 2015; Westbrook, et al., 2011; Zare, et al., 2013) and threat to patient safety (Cheragi, et al., 2013; David, et al., 2013; Fleming, et al., 2014). A recent study identified lacking in nursing curricula that should develop the nurse's competence in pharmacology and drug dosage calculation during the basic nursing training. The study results suggest that mathematical and conceptual drug dosage calculation skills "should be identified as a distinct competency in nursing curricula and continuing education program" p. 305 (Fleming, et al., 2014).

\section{Adverse out-comes}

Drug dosage miscalculation leads to medication errors that may result in serious adverse outcomes (Cheragi, et al., 2013; Fleming, et al., 2014). Presently health care reform in United states is taking positive initiatives in health policy and health care systems generally and specifically in hospitals while "Medicare has eliminated payments to hospitals for hospital- acquired conditions" p. 305 (David, et al., 2013).

Current literature indicates that drug dosage calculation is essential nursing proficiency that is so important to ensure patient safety and quality care (Athanasakis, 2012; Cheragi, et al., 2013; Fleming, et al., 2014; Shamsuddin \& Shafie, 2012; Tshiamo, et al., 2015). A recent study indicates that main cause of medication errors caused due to lack of pharmacological knowledge and study further shows that there was no statistically significant relationships between medication errors and nurses years of working experience, age, and working shifts (Cheragi, et al., 2013). A study conducted in Malaysia to assess the knowledge level of nurses related to preparation and administration of drugs indicated that intravenous medications errors cause most of life threatening situations (Shamsuddin \& Shafie, 2012). A recent study conducted in intensive care unit suggested that supervision to the nurses administering medications by more experienced ICU nurses in regular intervals is helpful in preventing medication errors (Agalu, Ayele, Bedada, \& Woldie, 2012).

A study conducted in Norway showed nurses poor knowledge and highest mean risk of medication error calling the immediate attention as nurses regularly have complete responsibility for medication management and drug dosage calculation and administration (Simonsen, et al., 2014). current literature reports that there is evidence that deaths from medication errors have been on the rise (Aronson, 2009).

Empirical literature suggested that nursing training program should give high importance on drug dosage calculation skills (Shamsuddin \& Shafie, 2012; Simonsen, et al., 2014). A recent study done in Australia indicated that intravenous drug administrations have a higher risk and severity of error than other medication administrations. A significant proportion of errors hint skill and knowledge deficiencies among nurses (Westbrook, et al., 2011).

\section{Intravenous drug errors}

Literature reports that $61 \%$ of serious adverse out-comes were associated with intravenous medication cited in (Shamsuddin \& Shafie, 2012). A study conducted in Iran showed that the most common type of medication errors (34.26\%) were linked with the intravenous injection doses faster than the recommended rate (Sohrevardi, et al., 2014). An observational study done in UK indicated that 265 intravenous (IV) drug errors were identified out of 483 drug preparations and 447 drug administration's (Taxis \& Barber, 2003). A study conducted in Australia for continuous infusions of IV fluids (parenteral nutrition and non-electrolyte) identified that the most common errors observed were wrong administration rate (Han, Coombes, \& Green, 2005). A study done in three countries UK, 
Germany and French identified that wrong dilutions and wrong rate of infusion administration were observed frequently, study suggested that intravenous infusions must be considered as a high risk interventions. These findings call urgent attention to develop effective policy and procedures for safe intravenous infusion therapy (Cousins, Sabatier, Begue, Schmitt, \& Hoppe-Tichy, 2005).

A study conducted in Malaysia reported that $61 \%$ of life threatening errors were linked with intravenous medications (Shamsuddin \& Shafie, 2012). A recent study reported that medication errors had been made by $64.55 \%$ of the nurses while, $31.37 \%$ of the participants reported potential medication errors identified and caught on the edge of occurrence related to wrong dosage and infusion rate (Cheragi, et al., 2013).

Another study indicates that during the assessment of knowledge level related to drug administration skills found less than 50\% of nurses able to calculate correct dosage of IV medications (Shamsuddin \& Shafie, 2012). Adverse out- come occur commonly among hospitalized patients, in United States medical errors has been estimated 3.7\% to $16.6 \%$ of hospital admissions cited in (Freedman, et al., 2002). A recent study conducted in Norway showed nurses poor knowledge and highest mean risk of medication error calling the immediate attention as nurses regularly have complete responsibility for medication management and drug dosage calculation and administration (Simonsen, et al., 2014). current literature reports that there is evidence that deaths from medication errors have been on the rise (Aronson, 2009).

Empirical literature suggested that nursing training program should give high importance on drug dosage calculation skills (Athanasakis, 2012; Cheragi, et al., 2013; Fleming, et al., 2014; Savage, 2015; Shamsuddin \& Shafie, 2012; Simonsen, et al., 2014; Tshiamo, et al., 2015). A recent study done in Australia indicated that intravenous drug administrations have a higher risk and severity of error than other medication administrations. A study conducted in Finland revealed that Practicing nurses $(n=62)$ were deficient with the skills they needed for accurate medication calculation, while $35 \%$ of the nurses achieved a score of $\geq 90$ and most errors were made when calculating intravenous drug dosage calculations (Grandell-Niemi, et al., 2001).

\section{Methodology}

PICOT approach was used to address the issue of drug dosage calculation proficiency of nurses on commencing their employment as follow:

Problem: A worldwide and well known Drug dosage calculation errors in hospital setting.

Population: Newly recruited nurses at Shifa International Hospital, Islamabad, Pakistan.

Intervention: Drug dosage Calculation Training Module

Comparison: Pre-test and post- test.

Outcome: Participants who scored $100 \%$ in post-test micro and macro dosage calculation were privileged to administer medication via oral, intramuscular (IM), intravenous (IV) and continuous infusion therapy.

Time: July 2016 to October 2016.

\section{Study design}

Participatory Action Research (PAR) approach was selected using pre and post test to assess the newly hired nurse's knowledge and skills related to drug dosage calculation. PAR is a teamwork between researcher and study participants in identification of the problem and finding its solution. The aim of PAR is realization and action including knowledge enhancement as researcher put efforts to empower study participants in developing and using new information (Polit \& Beck, 2004).

\section{Setting}

The study was conducted in Shifa International Hospital, Islamabad, Pakistan that is 500 bedded private tertiary hospital comprised of more than 100 critical beds (medical and surgical including pediatrics and neonatal). Shifa International Hospital also provides special services like cardiac surgery, renal transplant, liver transplant, corneal transplant hip and knee replacement inclusive many more special services. 


\section{Sample}

Purposive sampling technique was adopted $(n=135)$ all nurses on the commencement of their employment from July 2016 to October 2016 were selected to participate in the study at Shifa International Hospital, Islamabad Pakistan. Using pre-test and post-test approach for drug dosage calculation module in Nursing Education services successful nurses were to be assigned in different clinical areas Emergency Room (ER), Medical wards (male and female), Surgical ward (male and female), Stroke unit, Intensive care units: (Medical ICU, Medical step down, Surgical ICU and Surgical step down).

\section{Data collection}

Data was collected after the approval of Institutional Review Board (IRB) and the informed consent of the study participants from July 2016 to October 2016. The study tool contained 6 components to assess micro and macro drug dosage calculation proficiency of the nurses carrying total 50 marks. According to our hospital policy the study participants were expected to achieve full marks 50/50 (100\%) with no chance of error in drug dosage calculation to be privileged for medication administration. A recent literature cited many examples where nursing institutions pass nurses for medication administration even they achieved $70 \%$ score. Literature further argues that how $70 \%$ passing marks are acceptable when even small error may cause serious adverse event (Fleming, et al., 2014).

\section{Study tool}

A study tool taking before and after intervention approach assessed nurse's knowledge and proficiency for drug dosage calculation comprised of 6 components: metrics conversions, oral drug dosage, injections dosage, drips rate, blood and blood products rate and inotropic infusion related to life saving drug dosage calculations.

Questions in component 1: There were 10 questions to assess the metrics conversion skills carrying 1 mark each (total 10 marks). Question in component 2: contained 5 questions to assess oral dosage calculation carrying 2 marks each (total 10 marks). Question in component 3: comprised 5 questions to assess injections dosage calculation carrying 1 mark each (total 5 marks). Question in component 4: There were 5 questions for drip rate calculation carrying 2 marks each (total10 marks). Question in component 5: consisted 5 questions to calculate blood and blood products rate carrying 2 marks each (total 10 marks). Similarly, questions in component 6: There were 2 questions posed to judge the calculation skills in inotropic infusion related to life saving drug dosage calculation carrying 2.5 marks each (total 5 marks).

Internal and external validity of the tool was established by expert nurses 3 faculty members from Nursing Education Services and 5 on-board expert nurses working on clinical side. Pilot testing was done on $10 \%$ of the study sample that was excluded from the actual study. Conceptual framework teaching learning process: assessment, planning, implementation and evaluation was used to guide the study (Billings \& Halstead, 2005).

\section{Data collection procedure}

Upon completing hiring process in Human Resource Department on 4th day all newly employed nurses joined Nursing Education Services for 3 weeks orientation program as part of routine. Every month average 30 to 35 new nurses are employed to catch the nurse's shortage in the hospital. First day in Nursing Education Services all new nurses are pre-tested for their professional competencies and nursing knowledge including drug dosage calculation proficiency prior to commence the orientation program in Nursing Education Services department. The pre-test for drug dosage calculation was administered to each new group of nurses and based on pre-test results, 10 hours drug dosage calculation workshop ( 2 hours every day for 5 days) was conducted and each individual nurse was provided with rigorous exercises and examples of all types of drug dosage calculations under the close supervision of 2 nursing instructors and researcher to understand the concepts of micro and macro drug dosage calculations, standardized formulas and conceptual skills in mathematics. The study participants were provided with individualized assistance and coaching in addition to drug 
dosage calculation practice, standard formulas and workbooks. Small group work and individual home assignments for practice were also provided with guided teaching resources. While post- test was administered when the study participants felt comfortable and ready to attempt.

\section{Data analysis}

Pre-test and post-test responses were analyzed using SPSS (version 16). Descriptive statistics were applied using t-test with alpha $<0.05$ for comparison between pre-test and post-test score.

\section{Results}

\section{Demographic characteristics}

The sample constituted of nurses $(n=135)$ who recently joined study hospital and were inducted for orientation program. The socio demographic data of the study subjects were analyzed using descriptive statistics and were presented in terms of frequency and percentage. Majority of the participants $(n=98) 72.6 \%$ were females, aged between 21-25 Years $(n=104) 77.1 \%$. Education wise most of the participants $(n=133) 98.6 \%$ had General Nursing 3 Years Diploma most of them had additional one year specialty diploma in Midwifery/ ICU/ Cardiac/ Psychiatric/ Anesthesia/Accidental Emergency, while large number of participants $(n=92) 68.1 \%$ were fresh graduates (Table 1).

Table 1. Socio demographic variables $(n=135)$

\begin{tabular}{llll}
\hline Variables & & f & \% \\
\hline \multirow{2}{*}{ Gender } & Female & 98 & 72.6 \\
& Male & 37 & 27.4 \\
& $21-25$ & 104 & 77.1 \\
& $26-30$ & 26 & 19.2 \\
& $31-35$ & 5 & 30.7 \\
& BScN (4 years) / Post & 2 & 1.4 \\
Education & RN & & \\
Experience & Deneral Nursing & 133 & 98.6 \\
in Year & Fresh & & \\
& $1-3$ & 92 & 68.1 \\
& $4-6$ & 38 & 28.3 \\
& & 5 & 3.6 \\
\hline
\end{tabular}

${ }^{1}$ Additional One Year Specialization: Midwifery (97), ICU (6), Cardiac (11), Psychiatric (3), Anesthesia (3) Accidental Emergency (1).

Micro and macro drug dosage calculation proficiency data of 6 items was analyzed using SPSS (version 16). Descriptive statistics were applied using t-test with alpha $<0.05$ for comparison of pretest and post-test score. Item 1: conversions part showed pre-test mean score $2.42 \pm 1.52$ and post-test mean score $4.64 \pm 0.65$. P-value $<0.05$, paired t-test showed that the nurses gained significant knowledge after the education session. Item 2: oral dosage calculation showed pre-test mean score $5.31 \pm 3.19$ and post-test mean score $9.60 \pm 0.96$. P-value $<0.05$, paired $\mathrm{t}$ - test found the significant enhancement of knowledge in post-test scores. Item 3: injection dosage calculation showed pre-test mean score $4.12 \pm 3.15$ and post-test mean score $9.36 \pm 1.49$, P-value $<0.05$, paired t- test proved the significant increase in nurses knowledge in post-test. Item 4: drips rate calculation illustrate that pretest mean score 2.30 \pm 2.11 and post-test mean score $4.65 \pm 1.08$. P-value $<0.05$, paired t- test observed that the nurses gained significant knowledge after the intervention of education session. Item 5: blood and blood product rate calculation showed pre-test mean score $4.12 \pm 3.89$ and post-test mean score 8.92 \pm 2.50 . P-value $<0.05$, paired t- test established the significant improvement in nurses knowledge in post-test. Item 6: inotropes infusion rate calculation related to life saving drugs showed pre-test mean score $0.94 \pm 2.57$ and post-test mean score $7.93 \pm 3.48$. P-value $<0.05$, paired t-test found the 
significant enhancement of knowledge in post-test. While the overall paired t-test knowledge score in all 6 components achieved in pre-test by the respondents showed the mean score $19.21 \pm 16.43$ and post-test mean score $45.01 \pm 10.16$. P-value $<0.05$, Paired t-test revealed that the nurses gained significant knowledge after the education session (Table 2).

Table 2. Pre- test and post- test items wise scores (n135)

\begin{tabular}{|c|c|c|c|c|c|}
\hline \multirow[b]{2}{*}{ Items question (Total marks) } & \multicolumn{2}{|c|}{ Pre-test score } & \multicolumn{2}{|c|}{ Post-test score } & \multirow{2}{*}{$\begin{array}{l}\text { P-value } \\
\text { (Sig. 2- } \\
\text { tailed) }\end{array}$} \\
\hline & Mean & $\begin{array}{l}\text { Std. } \\
\text { Deviation }\end{array}$ & Mean & $\begin{array}{l}\text { Std. } \\
\text { Deviation }\end{array}$ & \\
\hline Metrics Conversions (10) & 2.42 & 1.52 & 4.64 & 0.65 & $<0.001$ \\
\hline Oral dosage calculation (10) & 5.31 & 3.19 & 9.60 & 0.96 & $<0.001$ \\
\hline Injections dosage calculation (5) & 4.12 & 3.15 & 9.36 & 1.49 & $<0.001$ \\
\hline Drips rate calculation (10) & 2.30 & 2.11 & 4.65 & 1.08 & $<0.001$ \\
\hline $\begin{array}{l}\text { Blood and blood product rate calculation } \\
\text { (10) }\end{array}$ & 4.12 & 3.89 & 8.92 & 2.50 & $<0.001$ \\
\hline Inotropic Infusion rate calculation (5) & 0.94 & 2.57 & 7.93 & 3.48 & $<0.001$ \\
\hline Overall score & 19.21 & 16.43 & 45.01 & 10.16 & $<0.006$ \\
\hline
\end{tabular}

In overall pre-test $(n=40) 29.63 \%$ received the score between $0-10$ (poor) and $(n=39) 28.89 \%$ of the participants received the score between $10.5-20$ (average). While ( $n=48) 35.56 \%$ of the participants scored between 20.5-40 (good and very good) and only few $(n=8) 5.92 \%$ of the study participants scored $40.5-<50$ (excellent). While in post-test the majority of the study participants $(n=111) 82.22 \%$ received the score between $40.5-\leq 50$ (excellent) while ( $\mathrm{n}=58 / 111) 42.96 \%$ achieve $100 \%$ accuracy score in safe drug dosage calculation. While some of the study participants $(n=23) 17.04 \%$ scored 20.5-40 that is good and very good (Table 3 ).

Table 3. Distribution of overall knowledge scores $(n=135)$

\begin{tabular}{lll}
\hline Knowledge Score & Pre-test f $(\%)$ & Post-test f $(\%)$ \\
\hline Poor $(0-10)$ & $40(29.63)$ & $0(0)$ \\
$\begin{array}{l}\text { Average }(10.5-20) \\
\text { Good (20.5-30) }\end{array}$ & $39(28.89)$ & $1(0.74)$ \\
$\begin{array}{l}\text { Very Good (30.5- } \\
\text { 40) }\end{array}$ & $23(18.52)$ & $7(5.19)$ \\
$\begin{array}{l}\text { Excellent (40.5- } \\
\leq 50)\end{array}$ & $8(5.92)$ & $16(11.85)$ \\
\hline
\end{tabular}

$1(\mathrm{n}=58 / 111$ achieved $100 \%$ accuracy in post test)

The analysis of score comparison qualification wise shows that there is no much difference in drug dosage calculation scores of the study participants acquiring general nursing 3 years diploma alone or having additional one year specialization courses as only few $(n=7 / 121) 5.18 \%$ achieved pre-test score 40.5-<50. Pre-test score of nurses having 3 years nursing diploma $(n=12) 8.8 \%$ also shows severe deficiency in drug dosage calculation skills that was significantly improved in post-test scores. However, BscN graduates $(\mathrm{n}=2) 1.48 \%$ performed much better in pre-test scoring $30.5-<50$ who were also able to score $100 \%$ in post test. However, overall post-test scores improved significantly. (Table 4). 


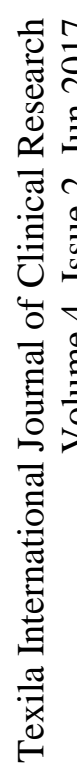

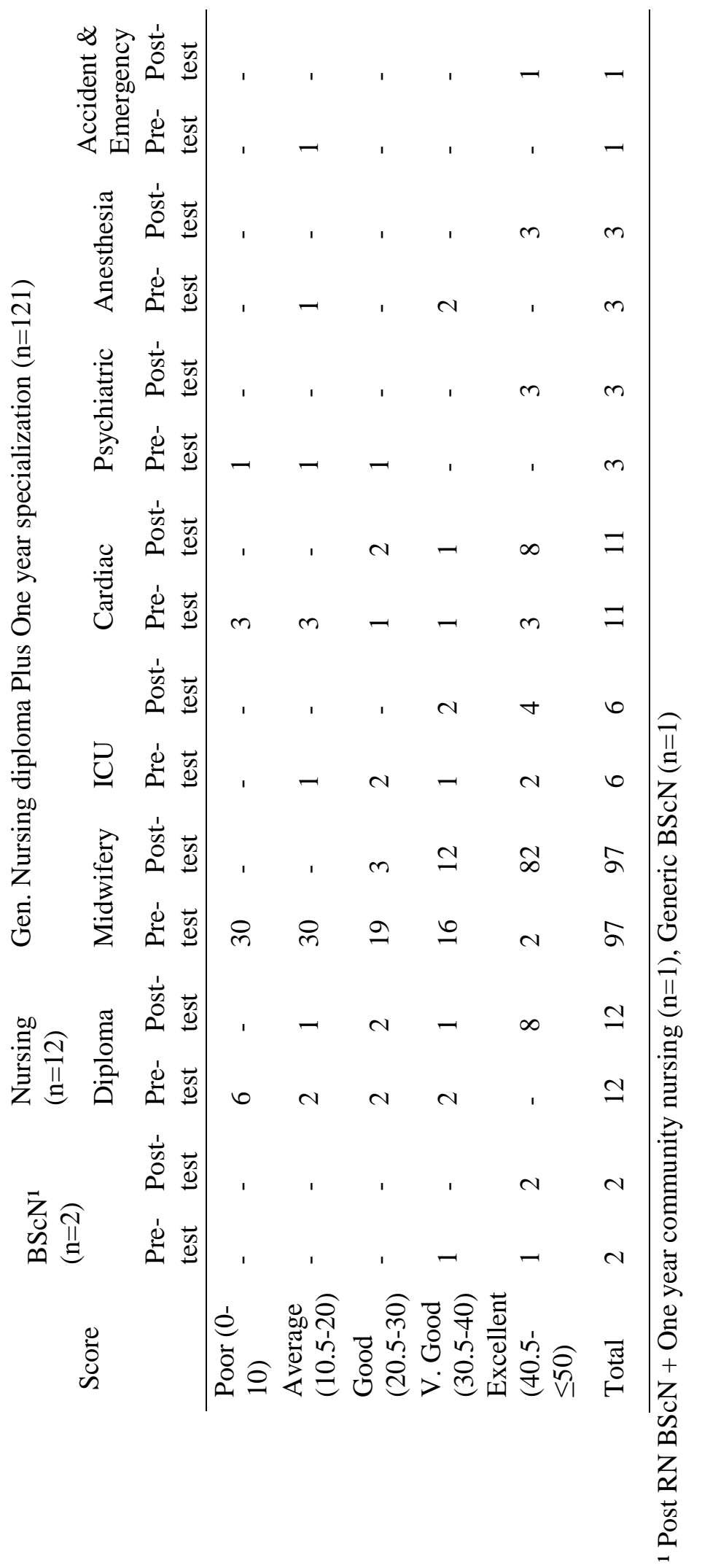


Score comparison of the study participant's experience- wise shows that there is no much difference in pre-test score between fresh graduate and experienced ones. While pre-test score shows that only few fresh nurses $(n=4) 2.97 \%$ achieved $40.5-<50$ score that is same for experienced ones. However, majority $(n=134) 99.25 \%$ scored $20.5-\leq 50$ that is good, very good and excellent level (Table 5).

Table 5. Score comparison with work experience of the study participants $(n=135)$

\begin{tabular}{lllllll}
\hline & \multicolumn{7}{l}{ Fresh $(\mathrm{n}=92)$} & \multicolumn{2}{l}{ Experience } \\
Score & $\begin{array}{l}\text { Pre- } \\
\text { test }\end{array}$ & $\begin{array}{l}\text { Post- } \\
\text { test }\end{array}$ & $\begin{array}{l}\text { Pre- } \\
\text { test }\end{array}$ & $\begin{array}{l}\text { Post- } \\
\text { test }\end{array}$ & $\begin{array}{l}\text { Pre- } \\
\text { test }\end{array}$ & $\begin{array}{l}\text { Post- } \\
\text { test }\end{array}$ \\
\hline Poor (0-10) & 29 & & 12 & - & - & - \\
$(\%)$ & $(21)$ & - & $(9)$ & - & - & - \\
Average (10.5-20) & 26 & - & 12 & 1 & & \\
$(\%)$ & $(20)$ & - & $(9)$ & $(1)$ & - & - \\
Good (20.5-30) & 18 & 4 & 5 & 3 & 2 & - \\
$(\%)$ & $(13)$ & $(3)$ & $(4)$ & $(2)$ & $(1.5)$ & \\
Very Good (30.5- & 15 & 11 & 6 & 3 & 2 & 1 \\
$40)$ & $(11)$ & $(8)$ & $(4)$ & $(2)$ & $(1.5)$ & $(1)$ \\
$(\%)$ & 4 & 77 & 3 & 31 & 1 & 4 \\
Excellent (40.5- & & & & & & \\
$\leq 50)$ & $(3)$ & $(57)$ & $(2)$ & $(23)$ & $(1)$ & $(3)$ \\
$(\%)$ & 92 & 92 & 38 & 38 & 5 & 5 \\
& $(68)$ & $(68)$ & $(28)$ & $(28)$ & $(4)$ & $(4)$ \\
\hline
\end{tabular}

The analysis of score comparison qualification wise shows that there is no much difference in drug dosage calculation scores of the study participants acquiring general nursing 3 years diploma alone or having additional one year specialization courses as only few $(n=7 / 121) 5.18 \%$ achieved pre-test score 40.5-<50. Pre-test score of nurses having 3 years nursing diploma $(n=12) 8.8 \%$ also shows severe deficiency in drug dosage calculation skills that was significantly improved in post-test scores. However, BscN graduates $(n=2) 1.48 \%$ performed much better in pre-test scoring $30.5-<50$ who were also able to score $100 \%$ in post test. However, overall post-test scores improved significantly. (Table 4).

Score comparison of the study participant's experience- wise shows that there is no much difference in pre-test score between fresh graduate and experienced ones. While pre-test score shows that only few fresh nurses $(n=4) 2.97 \%$ achieved $40.5-<50$ score that is same for experienced ones. Inability to calculate accurate dosages contribute to serious medication errors cited in (Fleming, et al., 2014). However, in post-test majority $(\mathrm{n}=134) 99.25 \%$ scored $20.5-\leq 50$ that is good, very good and excellent level (Table 5).

\section{Discussion}

Empirical literature highlighted the serious concern about nurse's drug dosage calculation proficiency (Cheragi, et al., 2013; Fleming, et al., 2014; Shamsuddin \& Shafie, 2012; Tshiamo, et al., 2015) and threat to patient safety (Cheragi, et al., 2013). There is lack of research in this area (Wright, 2010). Therefore, the current study was planned to evaluate the drug dosage calculation proficiency of registered nurses commencing employment.

Nursing Education Services at study hospital conducts drug dosage calculation proficiency preassessment of newly employed nurses that is part of three weeks orientation program as routine. As 
Drug Dosage Calculation and Safe Medication Administration Certification is basic requirement for nurses before starting in clinical areas at Shifa International Hospital. This orientation package includes drug dosage calculation proficiency module as well.

The study participant were taken in to confidence and assured that this exercise is to assess their knowledge and skills related to drug dosage calculation as an essential skill required for nurses so, they should not worry in case they do not score pre-test adequately. They were explained that during work hours, well designed training module will be provided to them to develop their competence in drug dosage calculation enabling them for safe medication preparation and administration. In addition, confidentiality and individual respect and dignity were observed all the time.

The study participants were found to be very enthusiastic to learn the drug dosage calculation proficiency that motivated them for informed consent with the right to with-draw any time during the study. The study cohort verbalized that this is first time for them to attend such structured program to build their competence in drug dosage calculation. During the course of the program the study participants took high interest to learn the mathematical concepts and standardized formulas to be used for drug dosage calculation. However, the learning capacity and pace varied for each individual that was taken care of by the concerned faculty members to facilitate the cohorts in learning throughout the whole process. This part of the information corresponds with previous researches that drug calculation proficiency must be developed among nurses on practice side through in-service education (Fleming, et al., 2014; Shamsuddin \& Shafie, 2012; Wright, 2010). Moreover, nursing curricula must address the nursing students need for capacity building in drug dosage calculation BscN level (Athanasakis, 2012; Fleming, et al., 2014; Sohrevardi, et al., 2014; Sulosaari, et al., 2015; Tshiamo, et al., 2015).

The empirical literature supports that nursing curriculum needs to be reviewed for effective integration of drug calculation proficiency and pharmacological knowledge otherwise student may graduate from the program with-out acquiring drug dosage calculation knowledge and proficiency that is prime important for nurses role cited in (Tshiamo, et al., 2015) lack of teaching opportunities regarding drug dosage calculation for nursing students and in-service activities for practicing nurses cited in (Fleming, et al., 2014).

The current study identified that years of nursing experience and additional specialty diploma had no influence on the level of score achieved by the study participants. The study results are similar to previous study done in Malaysia (Shamsuddin \& Shafie, 2012). In Pakistan this study result may be due to nurse's dependency on physicians that they receive calculated dosage prescriptions and they are system dependent in practice to verify such orders related to safe drug dosage calculation. However, this area needs further researches to identify the factual causes of knowledge and skill deficiency on nurses part related to drug dosage calculation. As literature supports that there is lack of research that medication errors are due to nurses poor numeracy skills (Fleming, et al., 2014).

While analyzing the main questionnaire comprised 6 components scenario based micro and macro drug dosage calculation suggested that item 1: conversions part that was based on 10 questions allocated 1 mark for each question showed pre-test mean score $2.42 \pm 1.52$ majority of the study participants $(n=104) 77 \%$ achieve the score 0 -30 that shows lack of nurses drug dosage calculation skills. The study results are congruent with previous literature (Fleming, et al., 2014; Shamsuddin \& Shafie, 2012). While post-test showed mean score $4.64 \pm 0.65$. P-value $<0.05$ and paired t- test showed that majority of the nurses $(n=127) 94 \%$ achieved score $30-\leq 50$ very good and excellent showing significant improvement after the drug calculation training. While item 2: oral dosage calculation was based on 5 questions allocated 2 marks for each question pre-test showed the mean score $5.31 \pm 3.19$ while majority scored $0-30$ and only $(n=31) 22.96 \%$ scored $30.5-<50$. Previous literature also indicated that nurses lack the drug dosage calculation skills (Cheragi, et al., 2013; Fleming, et al., 2014; Shamsuddin \& Shafie, 2012). Post-test showed significant improvement of mean score $9.60 \pm 0.96$. P-value $<0.05$ while paired t- test found the significant enhancement of knowledge among nurses after attending drug dosage calculation module.

Item 3: injection dosage calculation also contained 5 questions and allocated 1 mark for each question showed pre-test mean score $4.12 \pm 3.15$ majority $(n=104) 77 \%$ of the nurses scored $0-30$ previous study support this result (Cheragi, et al., 2013; Fleming, et al., 2014; Shamsuddin \& Shafie, 
2012). While post-test showed mean score $9.36 \pm 1.49$, P-value $<0.05$. Paired t-test proved the significant increase in nurse's knowledge.

The results of Item 4: drips rate calculation contained 5 question that was allocated 2 marks each (total10 marks) illustrate that the pre-test mean score $2.30 \pm 2.11$ showing that majority $(n=104) 77 \%$ scored 0-30. Similar studies suggested lack of nurses' knowledge in drip dosage calculation (Cheragi, et al., 2013; Fleming, et al., 2014; Shamsuddin \& Shafie, 2012). Post-test mean score improved 4.65 \pm 1.08 . P-value $<0.05$ paired $t$ - test observed that nurses gained significant knowledge after the intervention of drug dosage calculation session.

A study conducted in Australia for continuous infusions of IV fluids identified that the most common errors observed were wrong administration rate (Han, et al., 2005). A study done in three countries UK, Germany and French identified that wrong dilutions and wrong rate of infusion administration were observed frequently, study suggested that intravenous infusions must be considered as a high risk interventions. These findings call urgent attention to develop effective policy and procedures for safe intravenous infusions (Cousins, et al., 2005).

The study findings of item 5: related to blood and blood product rate calculation that was allocated 10 marks to 5 questions showed pre-test mean score $4.12 \pm 3.89$ and post-test mean score $8.92 \pm 2.50$. Pvalue $<0.05$, Paired t- test established the significant improvement in nurse's knowledge in post-test.

Item 6: inotropic infusion rate calculation related to life saving drug was allocated 5 marks for 2 questions that showed pre-test mean score $0.94 \pm 2.57$ and post-test mean score $7.93 \pm 3.48$. P-value < 0.05 , Paired t- test found the significant enhancement of knowledge in post-test. Empirical literature supports continuing education of the nurses that help reducing medication errors and especially high teaching priority for the new and complex medications coming in the hospitals (Anderson \& Townsend, 2010).

In overall pre-test $(n=40) 29.63 \%$ showed Knowledge score poor $(0-10)$ and $(n=39) 28.89 \%$ of the participants showed knowledge score average (10.5-20), while $(n=48) 35.56 \%$ of the participants obtained score 20.5-40 good and very good. However, only few $(n=8) 5.92 \%$ of the study participants scored excellent $40.5-<50$.

While in overall post-test the majority of the study participants $(n=111) 82.22 \%$ performed excellent and secured the highest score $40.5-\leq 50$; while ( $n=58 / 111) 42.96 \%$ achieve $100 \%$ accuracy score for safe drug dosage calculation and showing the significant impact of training session. In the study hospital newly hired nurses were assessed and given the opportunity to develop their competence in drug dosage calculation through this study as nurse's drug dosage calculation proficiency is very important for patient safety and delivery of quality care. In addition, we can control preventable medication errors and adverse events by reducing the chance of error by developing nurse's competence in drug dosage calculation. Moreover, we can make health care cost effective by shortening the length of stay in the hospital. Finally, we can gain public trust through provision of error free care or reduced medication errors rate.

The paired t-test knowledge score achieved by the respondents showed pretest mean score 19.21 \pm 16.43 and post-test mean score $45.01 \pm 10.16$. P-value $<0.05$, Paired t-test revealed that the nurses gained significant knowledge after the education session (Table 4).

All the study participants $(n=135)$ who were graduated from the different nursing educational institutions from all over the country failed the numeracy pre -test and could not achieve the required accuracy level in drug dosage calculation. Only $(\mathrm{n}=2) 1.48 \%$ who had $\mathrm{BscN}$ degree achieved the pretest score 30- $<50$. However, the passing marks were 50/50 (100\%) to reach the safe drug dosage calculation. However study participants failing in the pre-test were given 10 hours hands-on workshop along with practice questions and hospital drug dosage calculation protocol and guide as resource material to get themselves familiar with standard formulas to be used for accurate dosage calculations in different clinical situations. The training was facilitated by 2 nursing instructors and principal investigator.

The achievement of this study was that in post-test $(n=58) 42.96 \%$ of the study participants achieved $100 \%$ accuracy for safe drug dosage calculation and privileged for medication administration. While majority of the nurses $(n=77) 57 \%$ could not achieve $100 \%$ accuracy in posttest. So they were advised to re-appear for another post test or to repeat the modular program 
according to their comfort level until they reach to expected level of accuracy in drug dosage calculation. They were planned to be given extra time and support at their pace to help them to clarify difficulties and the key concepts involved in drug dosage calculation by arranging special tutorials. While these re-do results are not included in this study.

The study results suggested that at the commencement of employment nurses drug dosage calculation is extremely poor in the study hospital. It is very important for hospitals to asses this vital skill of nurses at the time of hiring. So, nurses lacking drug dosage calculation skills may be polished prior to assign them on clinical areas in order to ensure patient safety and quality care. This is most important area that is under investigated and warrants future researches (Wright, 2010). Drug dosage calculation knowledge and skill is essential competency for nurses that should be given high importance for in-service education and refresher trainings on regular basis. Similarly, Drug dosage calculation proficiency must be included in basic nursing curriculum so the newly graduate nurses acquire the knowhow of accuracy in drug dosage calculation once they join nursing jobs. The study findings supports that nursing curricula needs to be reviewed keeping in mind the importance of developing nurse's competence in pharmacology and drug dosage calculation knowledge and skills. previous empirical researches also suggested that drug dosage calculation skills must be acknowledged as an essential competency in basic nursing training and continuing education program for practicing nurses (Athanasakis, 2012; Cheragi, et al., 2013; Fleming, et al., 2014; Shamsuddin \& Shafie, 2012; Tshiamo, et al., 2015; Wright, 2010).

\section{Test of significance}

Null Hypostasis: Stated that mean score of pre-test $=$ mean score of post-test

Alternative Hypostasis: Stated that mean score of pre-test $\neq$ mean score of post-test

The mean score of pre-test was 19.21 and the mean score of post-test was 45.01, so there was enough evidence to reject $\mathrm{H}_{0}$.

P-value for all the pre-test and post-test responses was calculated using t-test. In all of the components a significant difference was observed as all 2-sided significance value for the complete set of questions came out to be highly significant $<0.005$.

\section{Limitation}

Limitation of the current study was a small sample size that comprised of only 4 month data. This would have been appropriate if data was collected at least over the 12 months period for generalization of the study findings. Although this study limits the generalization of the findings, the results supports the need for further research on a larger sample of the nurses commencing employment. A much larger study sample will validate the reliability and confirming the findings of this study.

\section{Conclusion}

In conclusion, nurses have vital responsibility to ensure safe drug administration to the patients. Several studies proved that nurses lack drug dosage calculation proficiency (Cheragi, et al., 2013; Fleming, et al., 2014; Shamsuddin \& Shafie, 2012; Tshiamo, et al., 2015). The pre-test of current study statistically established that the study participants were deficient of knowledge and proficiency regarding drug dosage calculation at commencement of employment. However, the post-test statistically proved that structured education program was highly effective to improve the knowledge and skill related to drug dosage calculation among nurses at the time of commencing employment.

The study results also showed that years of experience has no influence on the level of score achieved by the study participants. It may be due to nurses are not provided with effective training opportunities related to drug dosage calculation in-spite of their vital role in medication administration. Low scores in nurse's drug dosage calculation should be taken serious as such calculation errors and conceptual mistakes could cause life threatening medication errors or even deaths. In the light of current study it is recommended that drug dosage calculation skill must be considered key proficiency of the nurses that should be addressed aggressively in basic nursing curriculum as well as in-service education for on board nurses. 
In addition, this important skill must be assessed at the commencement of nurse's employment and they should be provided adequate training related to drug dosage calculation knowledge and proficiency in the interest of patient safety.

Empirical literature suggested that there is prime need to understand the causes of medication errors through universal and standardized reporting mechanisms (Michaels et al., 2010).

Although the sample size was small and the study findings cannot be generalized even then study has the implication on nursing practice, education, administration and research. Further, interventional/experimental research is warranted on larger sample to generalize the findings of this study.

\section{Implication of the study}

\section{Nursing practice}

At the time of commencement of employment nurses must be assessed for this important proficiency related to drug dosage calculation and provide them chance to up-date their related knowledge. Moreover, on- board nurses should be highly supported to polish their drug dosage calculation proficiency on regular basis. Hospitals must have standardized mechanism in-placed for nurse's in-service education and training related to drug dosage calculation to ensure patient safety.

\section{Nursing education}

Basic nursing curriculum must provide more hours to develop drug dosage calculation skills among student nurses. Nursing faculty members must acquire drug dosage calculation proficiency so they are enabled to teach and mentor students effectively.

\section{Nursing administration}

The nurse administrator can make use of these study findings to encourage the nurses for evidencebased practice and also transfer the knowledge among the student nurses during their clinical placement. In addition, seminars and workshop can be organized to strengthen the knowledge base related to drug dosage calculation.

The findings of the study should be used in basic nursing curriculum as well as basis of in-service education programs for nurses so their knowledge regarding drug dosage calculation may be enhanced.

\section{Nursing research}

The research findings and research design may be used as an avenue in future researches. The nurse researchers can promote further research on same topic to develop the body of knowledge for generalization of these findings and diverse aspects of the research for further inquiry into the problem.

\section{Acknowledgement}

The author wish to acknowledge:

a) The study participants to complete the study.

b) Nursing instructors Nazish kashif and Maria Tasleem for facilitation in teaching.

c) IRB and hospital management for providing the opportunity to conduct this study

d) Doctor Ammad Fahim (Assistant Director, Shifa Clinical Research Center) for his expert input on main script review.

\section{References}

[1]. Agalu, A., Ayele, Y., Bedada, W., \& Woldie, M. (2012). Medication administration errors in an intensive care unit in Ethiopia. Int Arch Med, 5(1), 15. doi: 10.1186/1755-7682-5-15.

[2]. Anderson, P., \& Townsend, T. (2010). Medication errors: Don't let them happen to you. American Nurse Today, 5(3), 23-27.

[3]. Aronson, J. K. (2009). Medication errors: Emerging solutions. British Journal of Clinical Pharmacology, 67(6), 589-591. doi: 10.1111/j.1365-2125.2009.03420.x. 
[4]. Athanasakis, E. (2012). Prevention of medication errors made by nurses in clinical practice. Health Science Journal. Retrieved from http://www.hsj.gr/medicine/prevention-of-medication-errors-made-by-nurses-inclinical-practice.pdf September 27, 2017.

[5]. Billings, D. M., \& Halstead, J. A. (2005). Teaching in Nursing: A Guide for Faculty (2nd ed.): Saunders.

[6]. Blais, K., \& Bath, J. B. (1992). Drug calculation errors of baccalaureate nursing students. Nurse Educator, 17(1), 12-15. doi: 10.1097/00006223-199201000-00010.

[7]. Cheragi, M. A., Manoocheri, H., Mohammadnejad, E., \& Ehsani, S. R. (2013). Types and causes of medication errors from nurse's viewpoint. Iranian Journal of Nursing and Midwifery Research, 18(3), 228-231.

[8]. Cousins, D. H., Sabatier, B., Begue, D., Schmitt, C., \& Hoppe-Tichy, T. (2005). Medication errors in intravenous drug preparation and administration: a multicentre audit in the UK, Germany and France. Quality and Safety in Health Care, 14(3), 190-195. doi: 10.1136/qshc.2003.006676.

[9]. Coyne, E., Needham, J., \& Rands, H. (2013). Enhancing student nurses' medication calculation knowledge; integrating theoretical knowledge into practice. Nurse Educ Today, 33(9), 1014-1019. doi: 10.1016/j.nedt.2012.04.006.

[10]. David, G., Gunnarsson, C. L., Waters, H. C., Horblyuk, R., \& Kaplan, H. S. (2013). Economic measurement of medical errors using a hospital claims database. Value in Health, 16(2), 305-310. doi: 10.1016/j.jval.2012.11.010.

[11]. Fleming, S., Brady, A. M., \& Malone, A. M. (2014). An evaluation of the drug calculation skills of registered nurses. Nurse Educ Pract, 14(1), 55-61. doi: 10.1016/j.nepr.2013.06.002.

[12]. Freedman, J. E., Becker, R. C., Adams, J. E., Borzak, S., Jesse, R. L., Newby, L. K., . . Cannon, C. (2002). Medication errors in acute cardiac care: An American Heart Association scientific statement from the Council on Clinical Cardiology Subcommittee on Acute Cardiac Care, Council on Cardiopulmonary and Critical Care, Council on Cardiovascular Nursing, and Council on Stroke. Circulation, 106(20), 2623-2629. doi: 10.1161/01.CIR.0000037748.19282.7D.

[13]. Grandell-Niemi, H., Hupli, M., \& Leino-Kilpi, H. (2001). Medication calculation skills of graduating nursing students in Finland. Adv Health Sci Educ Theory Pract, 6(1), 15-24.

[14]. Han, P. Y., Coombes, I. D., \& Green, B. (2005). Factors predictive of intravenous fluid administration errors in Australian surgical care wards. Qual Saf Health Care, 14(3), 179-184. doi: 10.1136/qshc.2004.010728.

[15]. McMullan, M., Jones, R., \& Lea, S. (2010). Patient safety: numerical skills and drug calculation abilities of nursing students and Registered Nurses. Journal of Advanced Nursing, 66(4), 891-899. doi: 10.1111/j.13652648.2010.05258.x.

[16]. Michaels, A. D., Spinler, S. A., Leeper, B., Ohman, E. M., Alexander, K. P., Newby, L. K., . . Gibler, W. B. (2010). Medication errors in acute cardiovascular and stroke patients: a scientific statement from the American Heart Association. Circulation, 121(14), 1664-1682. doi: 10.1161/CIR.0b013e3181d4b43e.

[17]. Polit, D. F., \& Beck, C. T. (2004). Nursing research principles and methods (Seventh ed.). Philadelphia: Lippincott Williams \& Wilkins.

[18]. Savage, A. R. (2015). Educational audit on drug dose calculation learning in a Tanzanian school of nursing. Afr Health Sci, 15(2), 647-655. doi: 10.4314/ahs.v15i2.44.

[19]. Shamsuddin, A. F., \& Shafie, S. D. (2012). Knowledge of Nurses in the Preparation and Administration of Intravenous Medications. Procedia - Social and Behavioral Sciences, 60, 602-609. doi: http://dx.doi.org/10.1016/j.sbspro.2012.09.429.

[20]. Simonsen, B. O., Daehlin, G. K., Johansson, I., \& Farup, P. G. (2014). Differences in medication knowledge and risk of errors between graduating nursing students and working registered nurses: comparative study. BMC Health Serv Res, 14, 580. doi: 10.1186/s12913-014-0580-7.

[21]. Sohrevardi, S. M., Mirjalili, M. R., Jarrahzadeh, M. H., Mirjalili, M., \& Mirzaei, E. (2014). Evaluating the Frequency of Errors in Preparation and Administration of Intravenous Medications in the Intensive Care Unit of Shahid-Sadoughi Hospital in Yazd. Journal of Pharmaceutical Care, 2(3), 114-119. doi: http://jpc.tums.ac.ir/index.php/jpc/article/view/57/57.

[22]. Sulosaari, V., Huupponen, R., Hupli, M., Puukka, P., Torniainen, K., \& Leino-Kilpi, H. (2015). Factors associated with nursing students' medication competence at the beginning and end of their education. BMC Medical Education, 15(1), 223. Retrieved from https://doi.org/10.1186/s12909-015-0513-0 September 27, 2017 doi:10.1186/s12909-015-0513-0. 
[23]. Taxis, K., \& Barber, N. (2003). Causes of intravenous medication errors: an ethnographic study. Quality \& safety in health care, 12(5), 343-347. doi: 10.1136/qhc.12.5.343.

[24]. Tshiamo, W. B., Kgositau, M., Ntsayagae, E., \& Sabone, M. B. (2015). The role of nursing education in preventing medication errors in Botswana. International Journal of Africa Nursing Sciences, 3, 18-23. Retrieved from http://www.africanursingsciencesjournal.com/article/S2214-1391(15)00013-X/pdf September 27, 2017 doi:10.1016/j.ijans.2015.06.001.

[25]. Westbrook, J. I., Rob, M. I., Woods, A., \& Parry, D. (2011). Errors in the administration of intravenous medications in hospital and the role of correct procedures and nurse experience. BMJ Qual Saf, 20(12), 10271034. doi: 10.1136/bmjqs-2011-000089.

[26]. Wright, K. (2004). An investigation to find strategies to improve student nurses' maths skills. Br J Nurs, 13(21), 1280-1287. doi: 10.12968/bjon.2004.13.21.17114.

[27]. Wright, K. (2010). Do calculation errors by nurses cause medication errors in clinical practice? A literature review. Nurse Educ Today, 30(1), 85-97. doi: 10.1016/j.nedt.2009.06.009.

[28]. Zare, Z. G., Purfarzad, Z., \& Adib-Hajbaghery, M. (2013). Medication Management Skills of Nursing Students: Comparing the Students and Their Instructors Evaluation in two Universities. [Research Article]. Nurs Midwifery Stud, 1(3), 139-145. doi: 0.5812/nms.8555. 